\title{
WAR AND DEMOCRACY
}





\section{WAR AND DEMOCRACY Labor and the Politics of Peace}

Elizabeth Kier 


\section{Copyright ( 2021 by Cornell University}

All rights reserved. Except for brief quotations in a review, this book, or parts thereof, must not be reproduced in any form without permission in writing from the publisher. For information, address Cornell University Press, Sage House, 512 East State Street, Ithaca, New York 14850. Visit our website at cornellpress.cornell.edu.

First published 2021 by Cornell University Press

\section{Library of Congress Cataloging-in-Publication Data}

Names: Kier, Elizabeth, 1958- author.

Title: War and democracy : labor and the politics of peace / Elizabeth Kier.

Description: Ithaca [New York] : Cornell University Press, 2021. |

Includes bibliographical references and index.

Identifiers: LCCN 2020043173 (print) | LCCN 2020043174 (ebook) | ISBN 9781501756405 (hardcover) | ISBN 9781501756412 (ebook) | ISBN 9781501756429 (pdf)

Subjects: LCSH: Politics and war. | Democracy. | World War, 1914-1918 -Influence. | World War, 1914-1918 — Social aspects—Great Britain. | World War, 1914-1918 — Social aspects—Italy. | Labor movement—Political aspects—Great Britain. | Labor movement—Political aspects—Italy. Classification: LCC D639.D45 K54 2021 (print) | LCC D639.D45 (ebook) | DDC $940.3 / 1-\mathrm{dc} 23$

LC record available at https://lccn.loc.gov/2020043173

LC ebook record available at https://lccn.loc.gov/2020043174

Jacket illustration: Cartoon by Ancerenaz, La Baionnette, September 14, 1916, p. 588. Mary Evans Picture Library. 
To Jon 
